Review

\title{
Sleep and Cognition in Community-Dwelling Older Adults: A Review of Literature
}

\section{Glenna S. Brewster ${ }^{1,2, *}$, Miranda Varrasse ${ }^{3}$ and Meredeth Rowe ${ }^{1}$}

1 College of Nursing, University of South Florida, 12901 Bruce B. Downs Blvd., MDC Box 22, Tampa, FL 33612, USA; E-Mail: mrowe1@health.usf.edu

2 School of Medicine, University of Pennsylvania, 3624 Market Street, Suite 205, Philadelphia, PA 19104, USA

3 School of Nursing, University of Pennsylvania, Claire M. Fagin Hall, 418 Curie Boulevard, Philadelphia, PA 19104, USA; E-Mail: mvarr@nursing.upenn.edu

* Author to whom correspondence should be addressed; E-Mail: gbrewste@health.usf.edu; Tel.: +1-813-498-8774.

Academic Editors: Tracey L. Yap and Melissa Batchelor-Murphy

Received: 30 June 2015 / Accepted: 24 November 2015 / Published: 4 December 2015

\begin{abstract}
Changes in sleep and cognition occur with advancing age. While both may occur independently of each other, it is possible that alterations in sleep parameters may increase the risk of age-related cognitive changes. This review aimed to understand the relationship between sleep parameters (sleep latency, wake after sleep onset, sleep efficiency, sleep duration, general sleep complaints) and cognition in community-dwelling adults aged 60 years and older without sleep disorders. Systematic, computer-aided searches were conducted using multiple sleep and cognition-related search terms in PubMed, PsycINFO, and CINAHL. Twenty-nine manuscripts met the inclusion criteria. Results suggest an inconsistent relationship between sleep parameters and cognition in older adults and modifiers such as depressive symptoms, undiagnosed sleep apnea and other medical conditions may influence their association. Measures of sleep and cognition were heterogeneous. Future studies should aim to further clarify the association between sleep parameters and cognitive domains by simultaneously using both objective and subjective measures of sleep parameters. Identifying which sleep parameters to target may lead to the development of novel targets for interventions and reduce the risk of cognitive changes with aging.
\end{abstract}


Keywords: older adults; sleep parameters; cognition; attention; executive function; verbal fluency; memory

\section{Introduction}

Alterations in sleep and cognition are associated with advancing age [1-3]. Approximately 50\% of older adults report that they experience sleep problems [4]. Specifically, older adults report subjective reductions in total sleep time (TST) and sleep efficiency (SE) as well as increases in sleep latency (SL) and wake after sleep onset (WASO) [4]. Changes in sleep parameters add complexity to age-related cognitive changes, as sleep is necessary for healthy brain and bodily function and repair [5,6]. Sleep disturbances may contribute to inadequate central nervous system restoration [7] with the potential to impair cognitive function. There is extensive literature on the role of sleep in memory consolidation [8] but two recent reviews have concluded that the association between sleep and cognition is inconsistent across studies $[9,10]$. This review is broader in scope in that it specifically examines the associations between specific sleep parameters and the domains of and global cognition in community-dwelling older adults with no complaints of insomnia or other sleep disorders. It is important to determine which sleep parameters have the greatest effect on cognition so that researchers can identify modifiable risk factors for cognitive impairment and know which parameters to target for novel interventions that can potentially decrease the risk for cognitive impairment [10,11].

The objective for this exploratory review of sleep parameters and cognition in community-dwelling adults 60 years and older was to understand the relationships between sleep parameters (sleep latency, wake after sleep onset, sleep efficiency, sleep duration, and general sleep complaints), and the domains of cognition (Executive Function, Attention, Episodic Memory, Working Memory, Processing Speed) and global cognition.

\section{Methods}

Systematic, computer-aided searches were conducted using PubMed, PsycINFO, and CINAHL with the following terms: "cognitive", "cognition", "older", "sleep", "attention", "episodic memory", "executive function", "processing speed", "verbal fluency", and "working memory". No limits were applied. Reference lists of original and review articles were examined to identify additional relevant publications. To qualify for inclusion in the review, the studies had to include participants who had a mean age of 60 years or older, with no complaints of insomnia, sleep disorders, or cognitive impairment at baseline, and were living independently in the community. The articles also had to report outcome measures of cognition and/or cognitive impairment, have predictor variables of subjective or objective sleep parameters, report original quantitative analyses, and be published in a peer-reviewed journal.

After removing 3053 duplicates, 735 articles were screened for relevance (See Figure 1). Titles were reviewed and excluded if the title or abstract included a population other than older adults; a sample with sleep disorders; a control for clinical groups; contained the words hospitalized or inpatient; were disease or medication specific; did not contain human subjects; were primarily focused on tool development or measurement testing; were specific to sleep architecture; or did not contain sleep parameters as the 
dependent variable and cognition as independent variable. Forty-one full text articles were assessed and 12 were excluded based on age $<60$ or one of the aforementioned sleep parameters was not a predictor of cognition. Twenty-nine articles were identified as fulfilling the inclusion criteria and were included in the review. It must be noted that Blackwell, et al. [12] and Blackwell, et al. [13] used data from the Study of Osteoporotic Fractures and Devore, et al. [14] and Tworoger, et al. [15] used data from the Nurses' Health Study. Articles were reviewed by two authors and discrepancies were discussed. A review of literature table was completed to report the findings of the studies (Table 1).

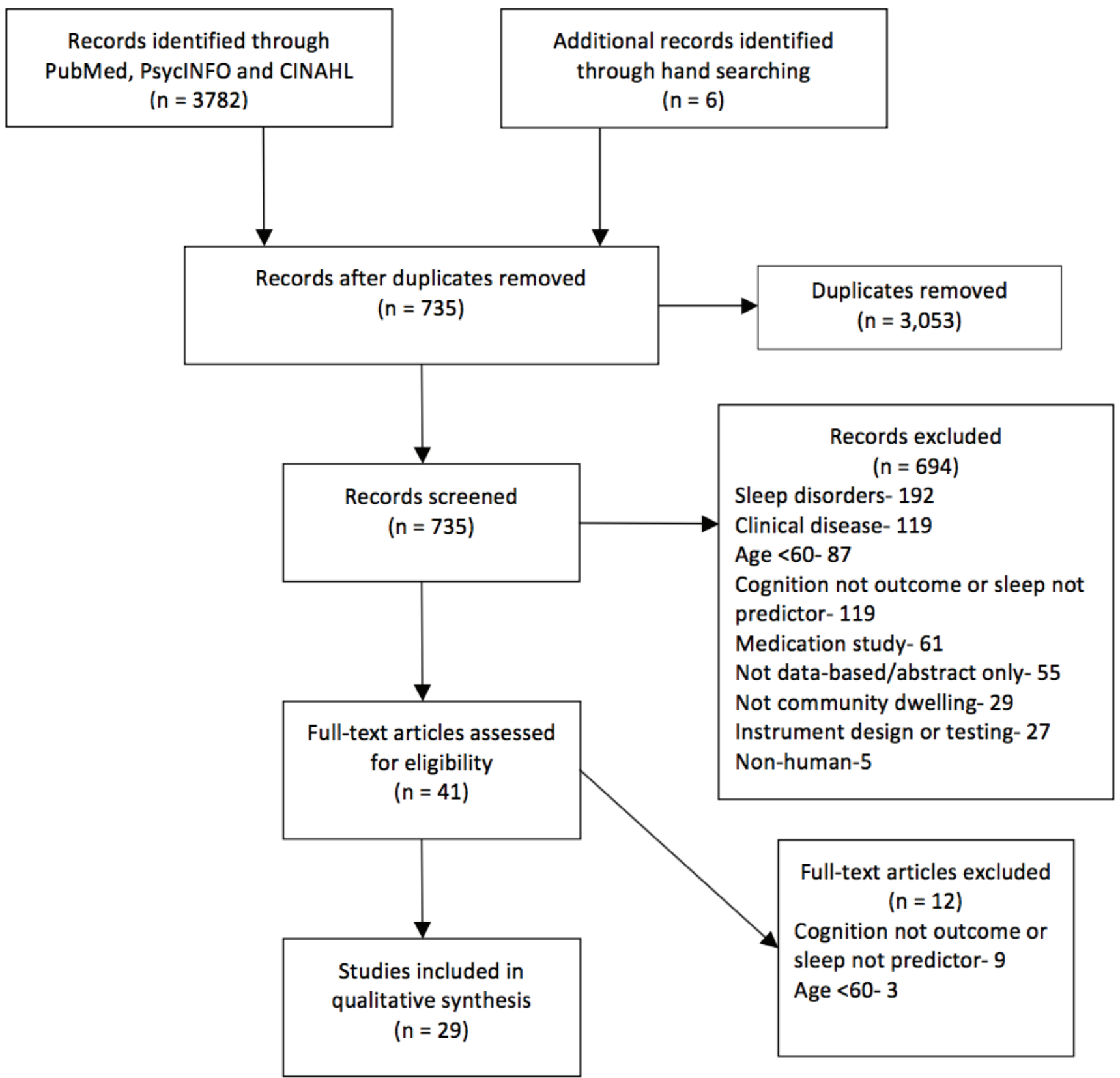

Figure 1. Flow diagram of literature review search for sleep and cognition in older adults. 


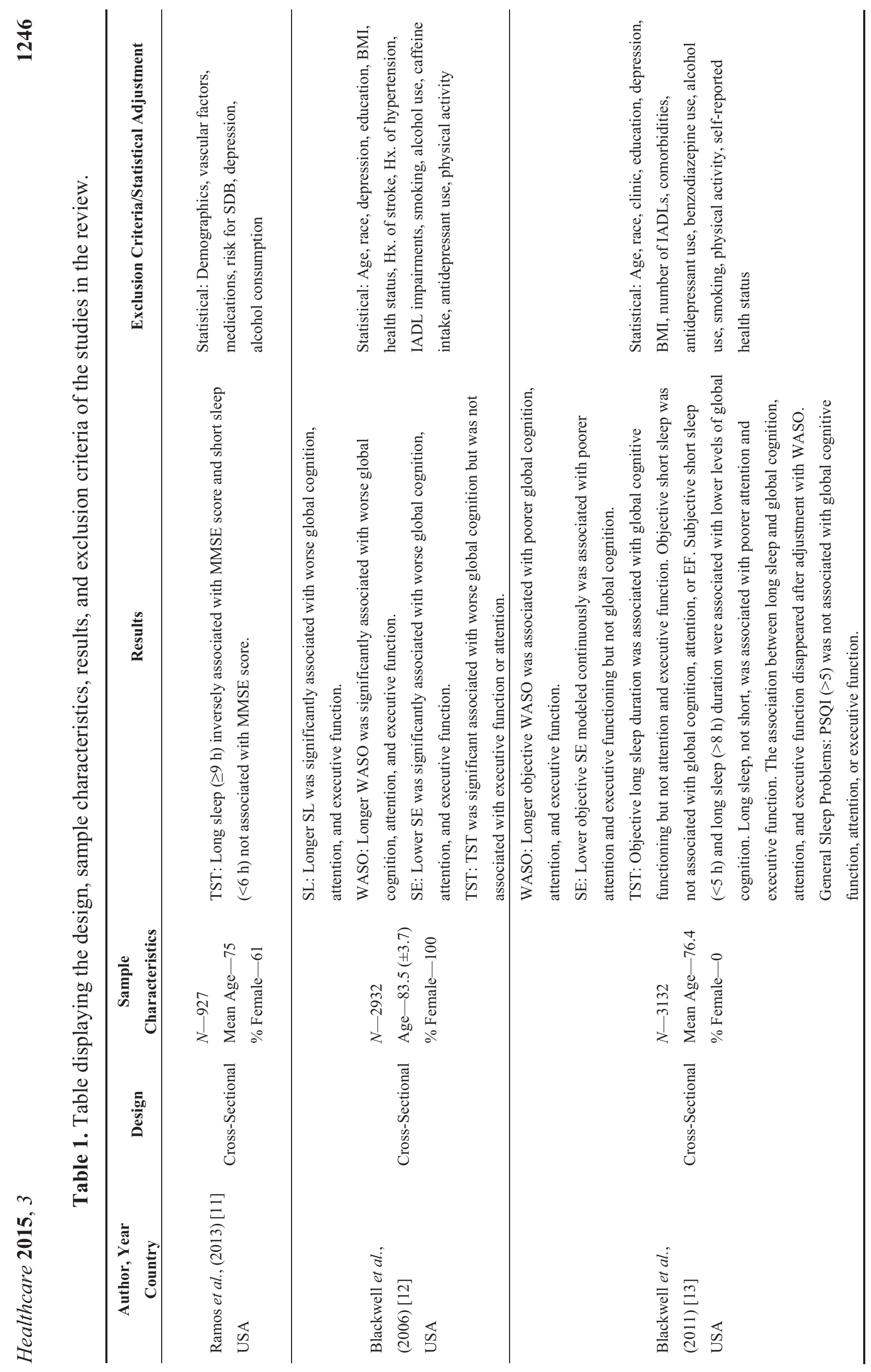




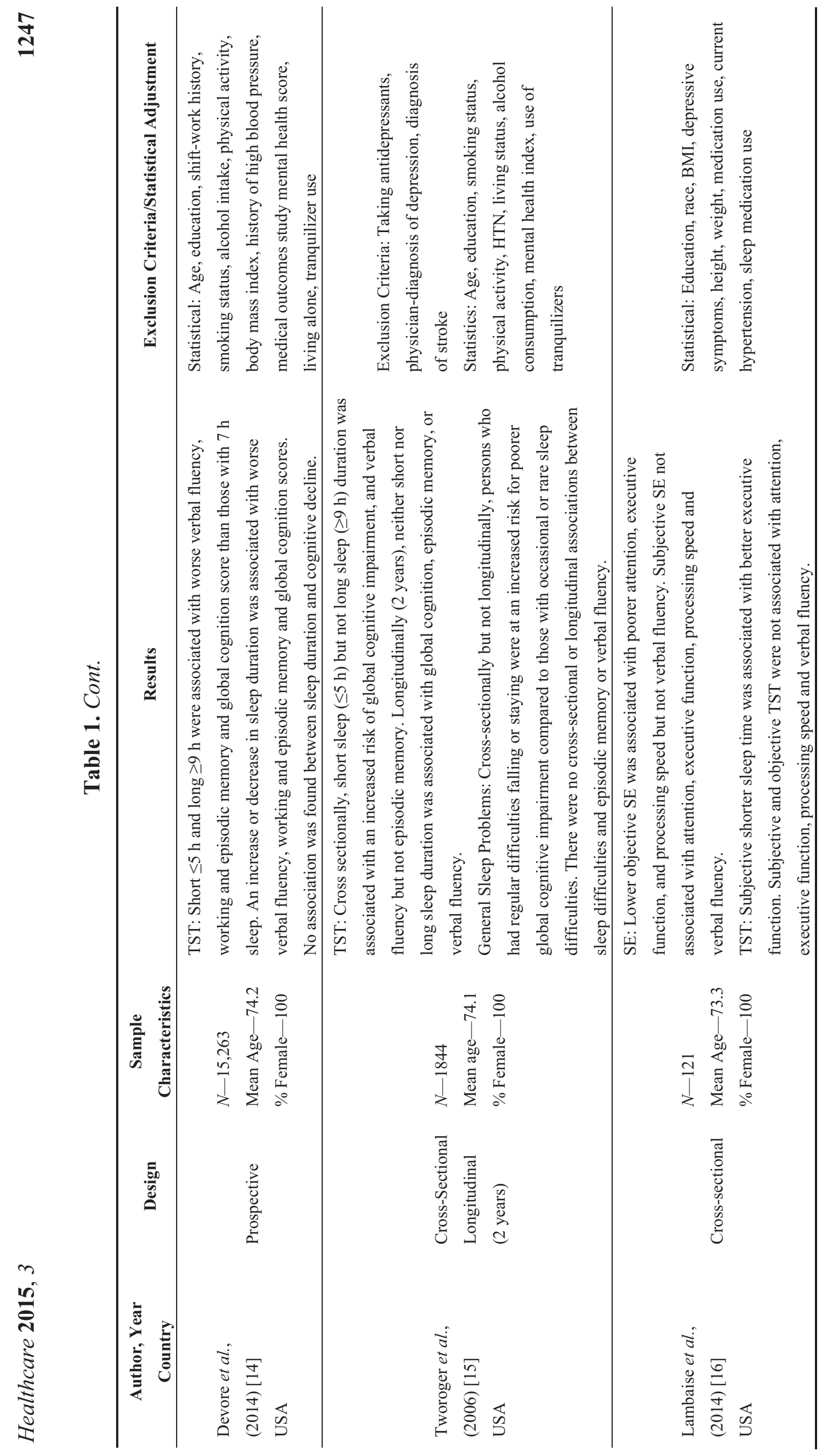




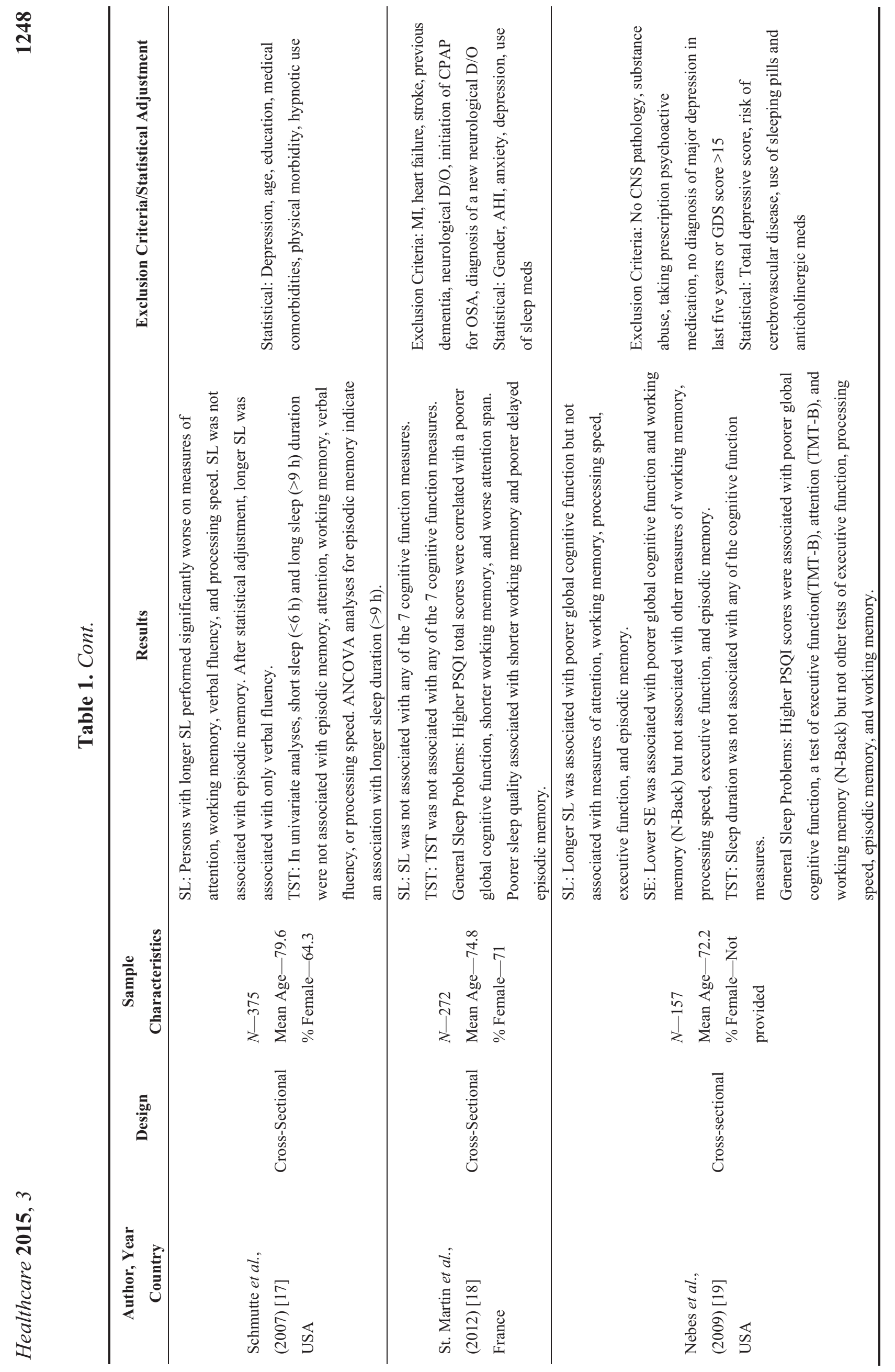




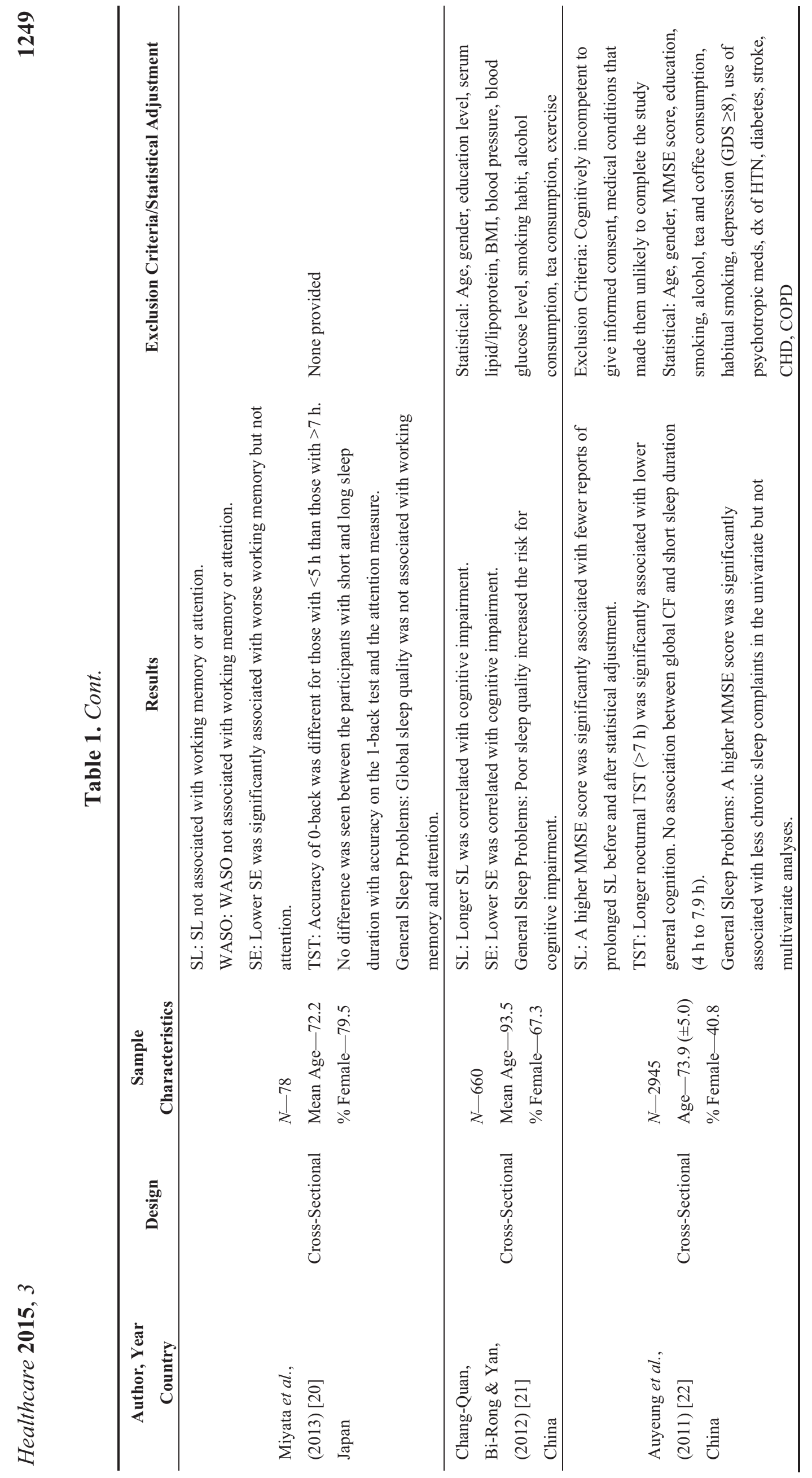




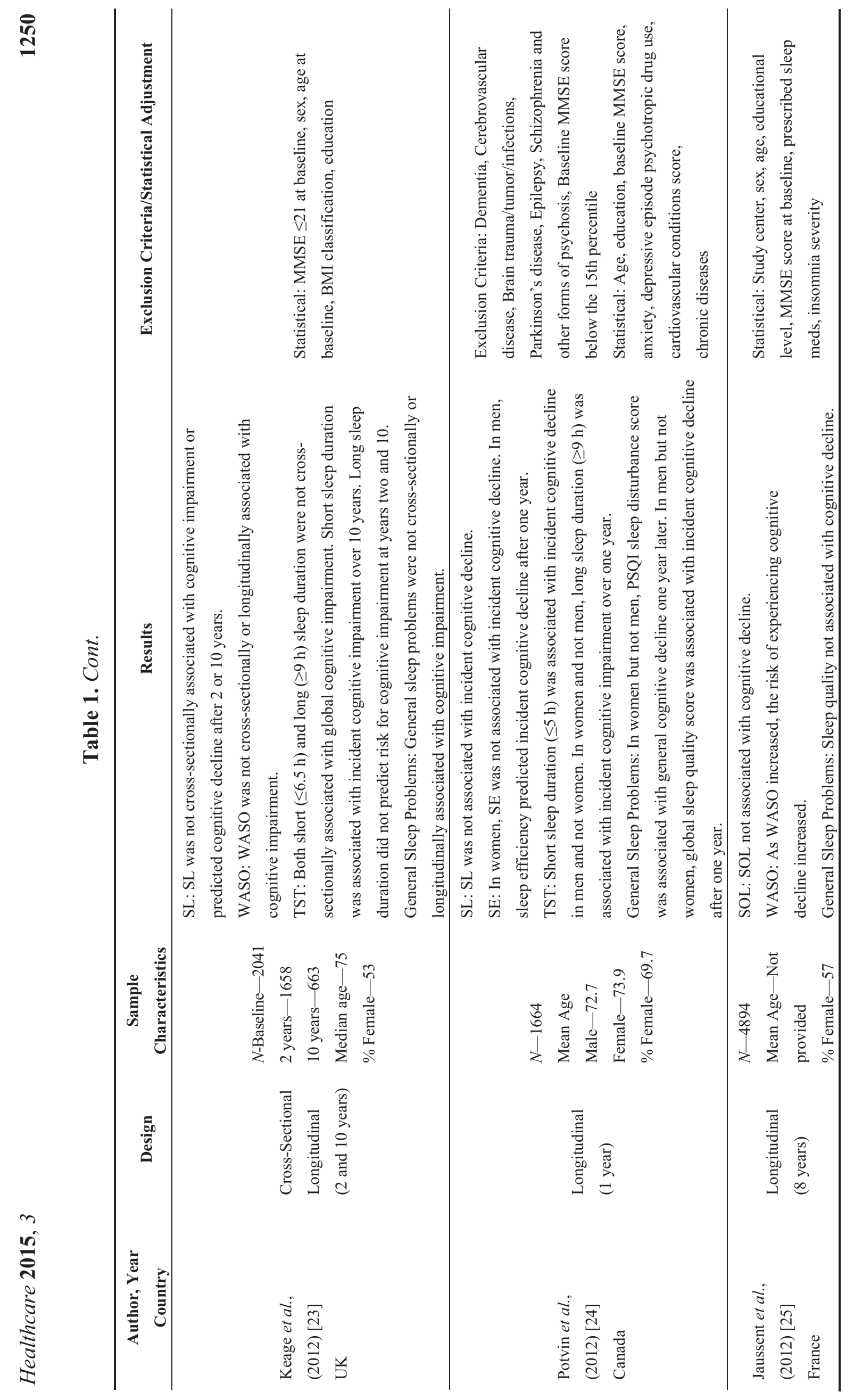




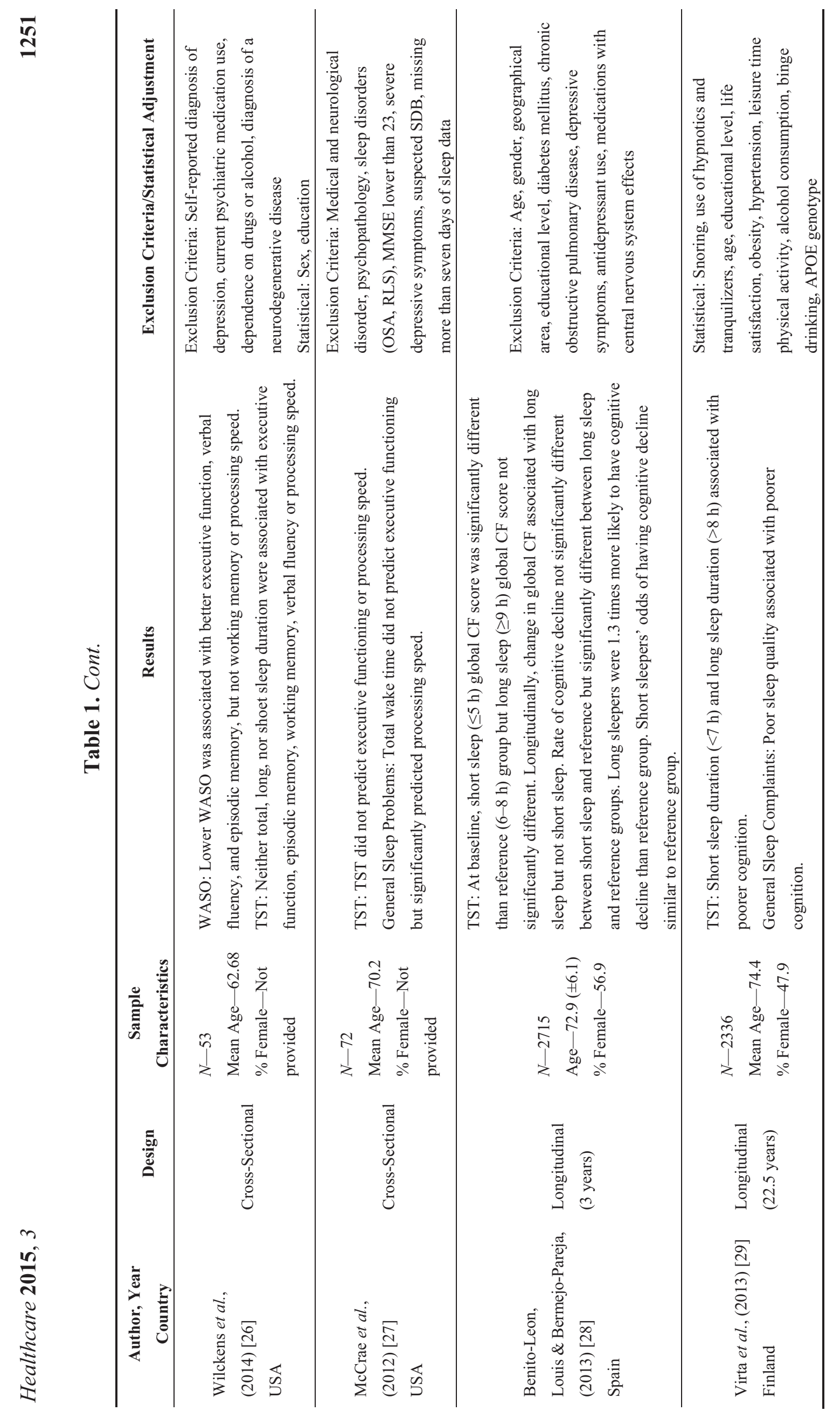




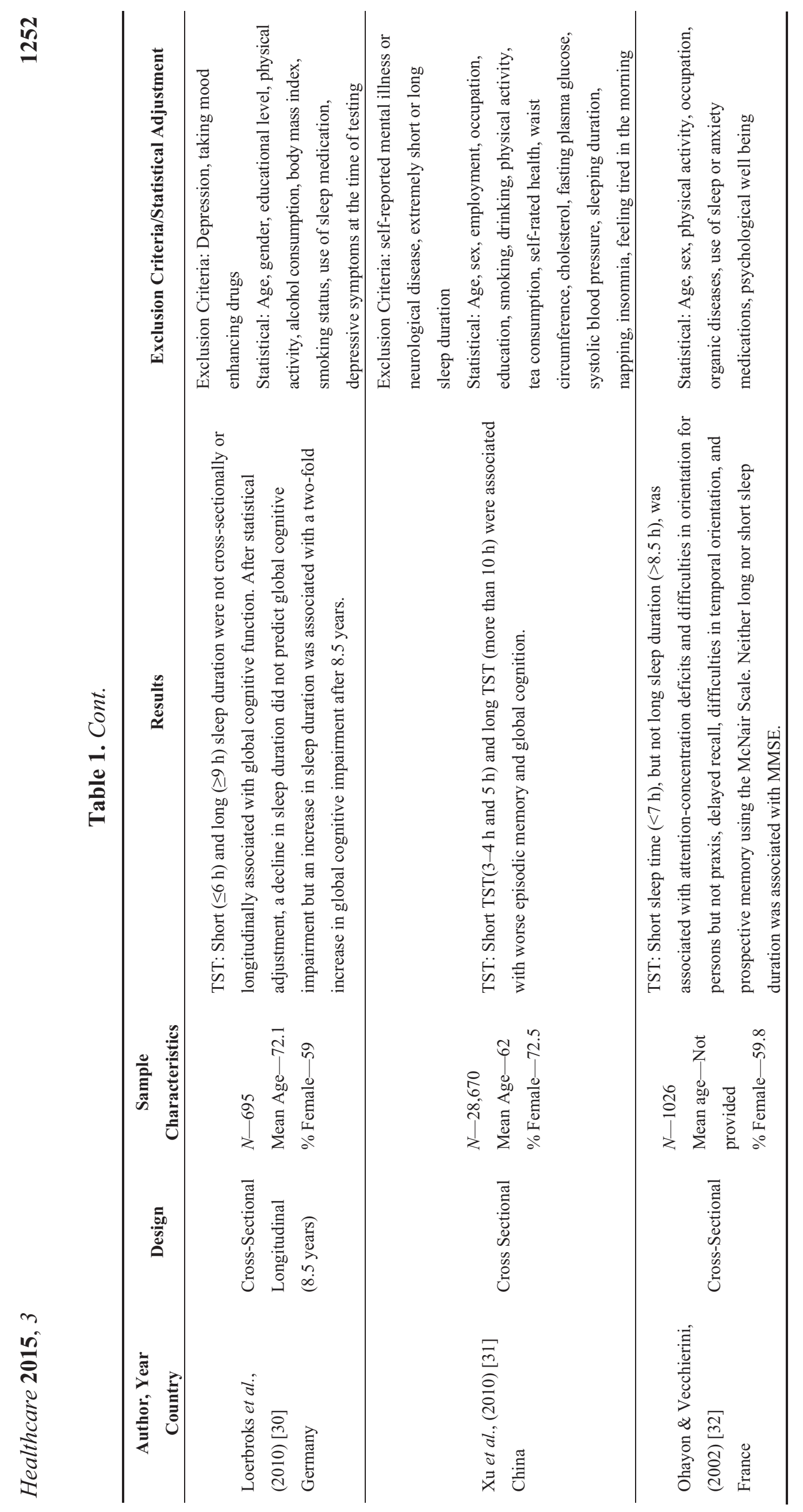




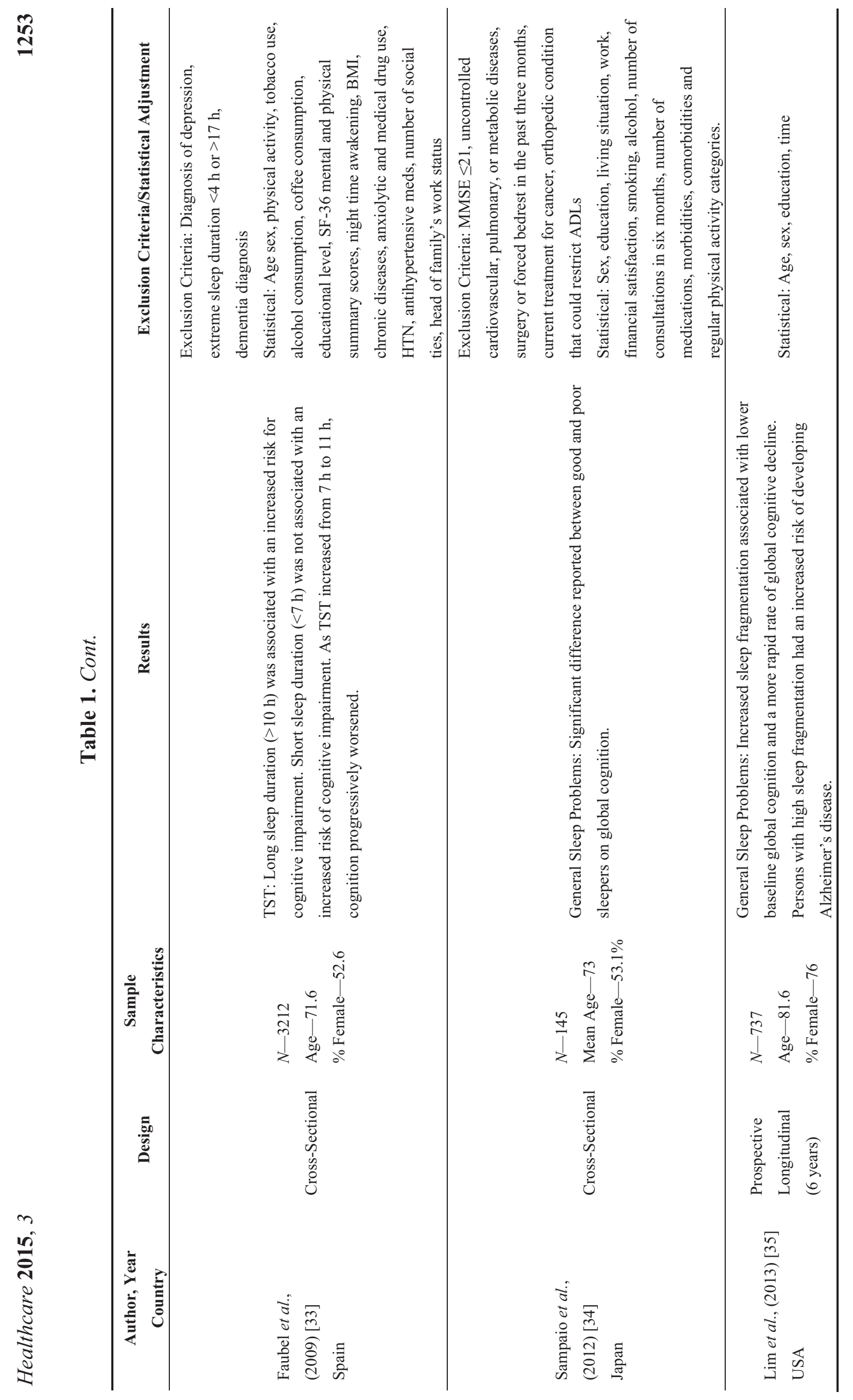




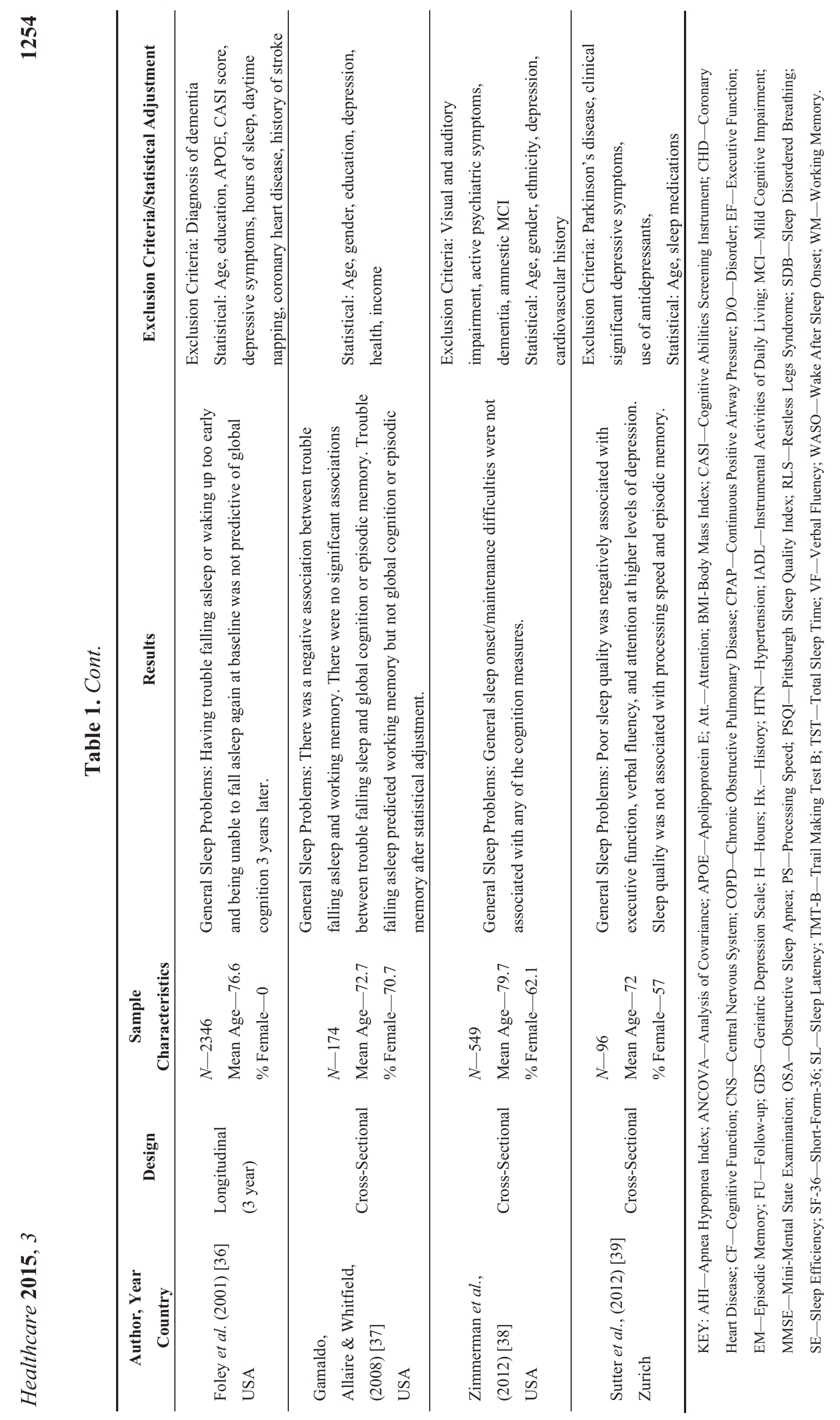




\section{Results}

Investigator-developed questionnaires, or proxy measures of sleep, were used to subjectively measure sleep in the majority of the studies. Also, each of these measures evaluated the sleep parameters using different questions. The Pittsburgh Sleep Quality Index (PSQI) [40] was another frequently used instrument for subjective sleep assessment. Sleep diaries were used in three of the studies. Of the studies that used actigraphy to measure sleep objectively, Blackwell, et al. [13] and Lambiase, et al. [16] used a sleep diary concurrently (See Table 2).

Table 2. Table displaying the measures used to assess sleep.

\begin{tabular}{|c|c|}
\hline Subjective & Objective \\
\hline Investigator-Developed Sleep Questionnaire & Actigraphy \\
\hline Ramos et al., (2013) [11]; Devore et al., (2014) [14]; Tworoger et al., (2006) [15]; & Blackwell et al., (2006) [12]; \\
\hline Schmutte et al., (2007) [17]; Auyeung et al., (2013) [22]; Keage et al., (2012) [23]; & Blackwell et al., (2011) [13]; \\
\hline Jaussent et al., (2012) [25]; Virta et al., (2013) [29]; Loerbroks et al., (2010) [30]; & Lambaise et al., (2014) [16]; \\
\hline Xu et al., (2010) [31]; Faubel et al., (2009) [33]; Sampaio et al., (2012) [34]; & Miyata et al., (2013) [20]; \\
\hline Lim et al., (2013) [35]; Foley et al., (2001) [36]; Gamaldo, Allaire \& Whitfield, (2008) [37] & Lim et al., (2013) [35] \\
\hline Pittsburgh Sleep Quality Index & SensaWear \\
\hline Blackwell et al., (2011) [13]; St. Martin et al., (2012) [18]; Nebes et al., (2009) [19]; & Wilckens et al., (2014) [26] \\
\hline Miyata et al., (2013) [20]; Chang-Quan, Bi-Rong \& Yan, (2012) [21]; & \\
\hline Potvin et al., (2012) [24]; Sutter et al. (2012) [39] & \\
\hline \multicolumn{2}{|l|}{ Sleep Diary } \\
\hline \multicolumn{2}{|l|}{ Blackwell et al., (2011) [13]; Lambaise et al., (2014) [16]; } \\
\hline \multicolumn{2}{|l|}{ McCrae et al., (2012) [27] } \\
\hline \multicolumn{2}{|l|}{ Sleep-EVAL System } \\
\hline \multicolumn{2}{|l|}{ Blackwell et al., (2011) [13]; Lambaise et al., (2014) [16]; } \\
\hline \multicolumn{2}{|l|}{ McCrae et al., (2012) [27] } \\
\hline \multicolumn{2}{|l|}{ Medical Outcomes Study Sleep Scale } \\
\hline Zimmerman et al., (2012) [38] & \\
\hline
\end{tabular}

There was also a large variety of tests and instruments that were used to assess the domains of cognition and global cognition (See Table 3). The Mini-Mental State Exam (MMSE) [41] was used in more than half of the studies to assess global cognition. In addition, some of the tests in this study overlapped domains, making it difficult to demonstrate clear differences in the association between sleep parameters and specific domains of cognition. For example, Trail Making Part B is used to measure both attention and executive function. However, this is an issue that plagues cognition research [42,43] and is difficult to avoid.

In order to understand the relationship between sleep and cognition, each parameter of sleep and its association with cognition will be discussed in the following section (see Tables 4 and 5). 


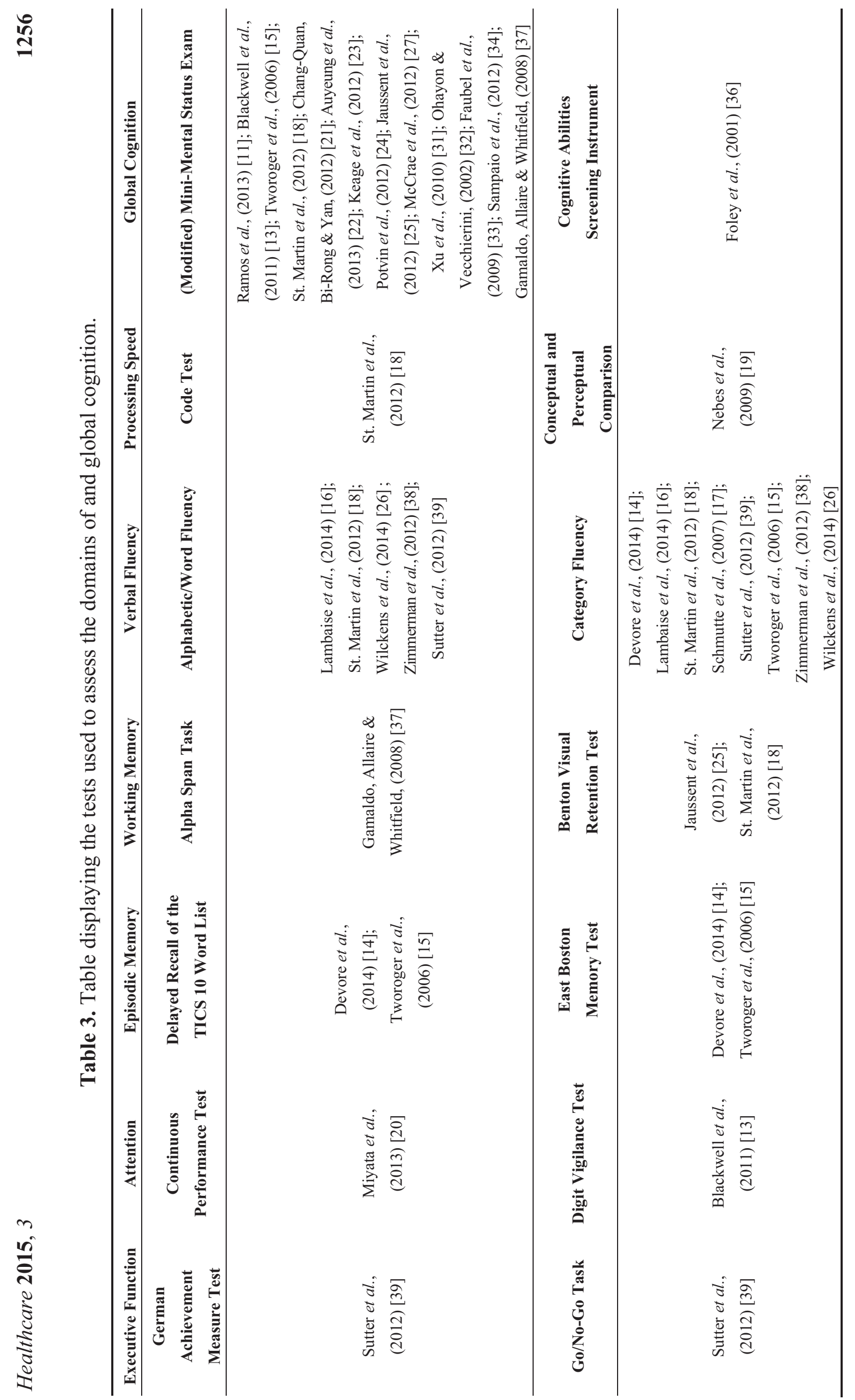




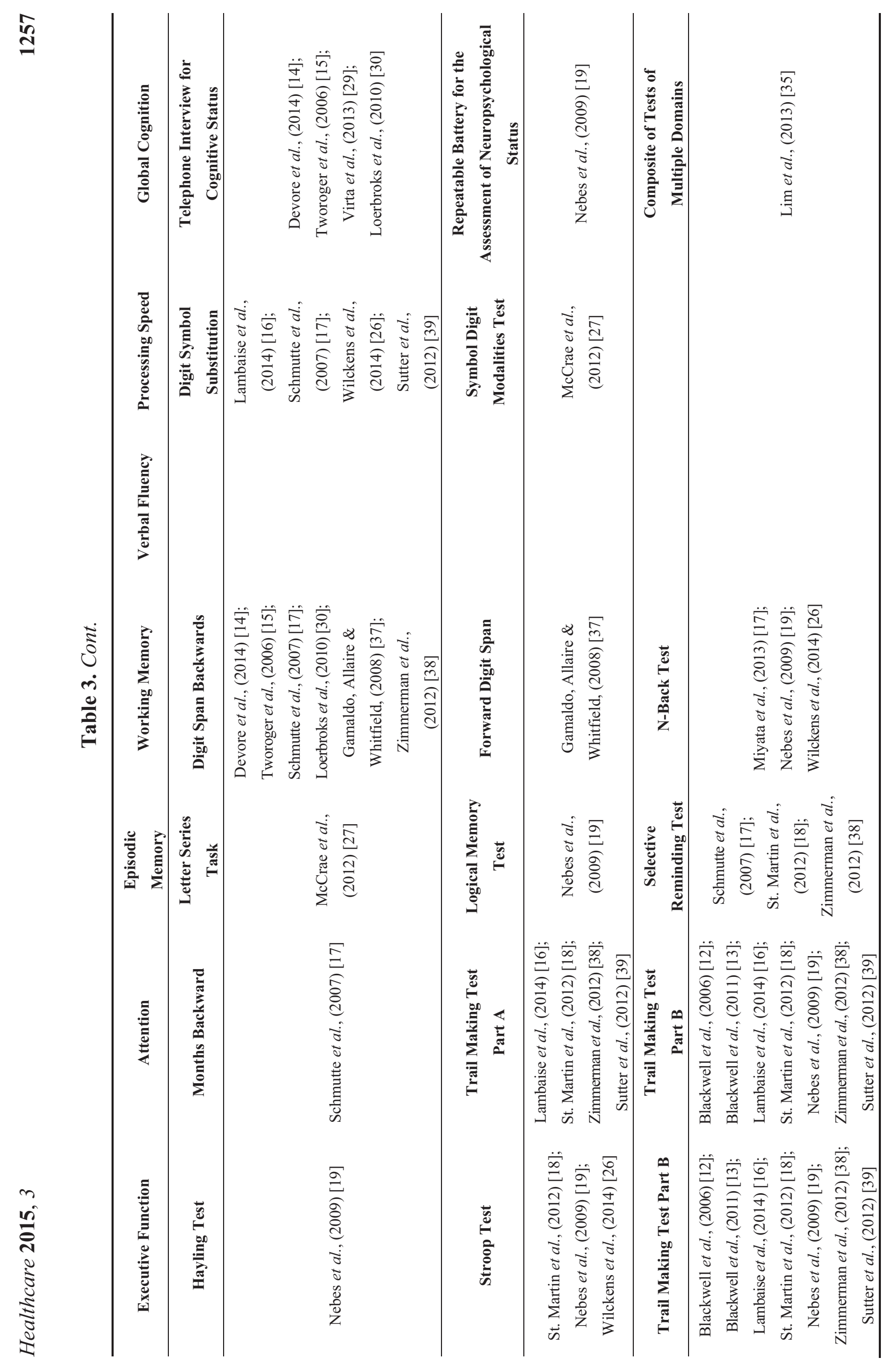




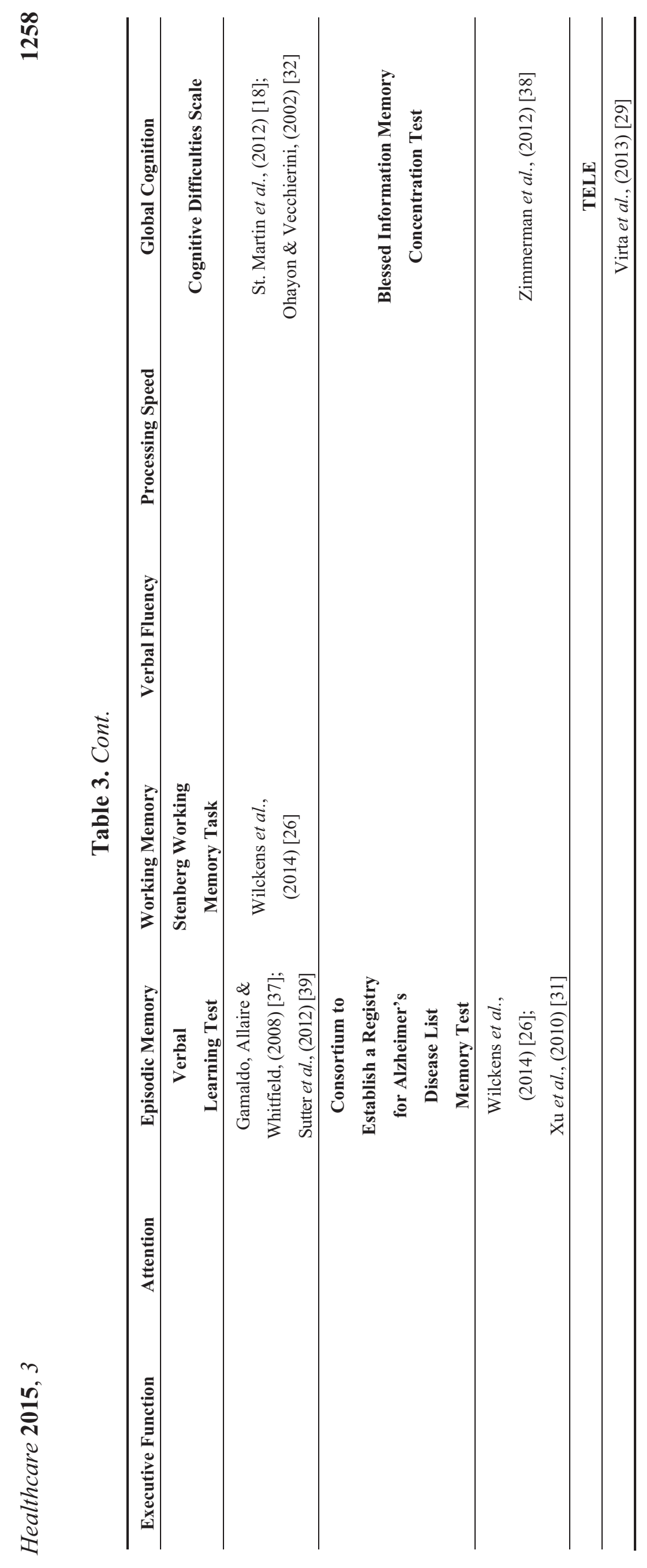




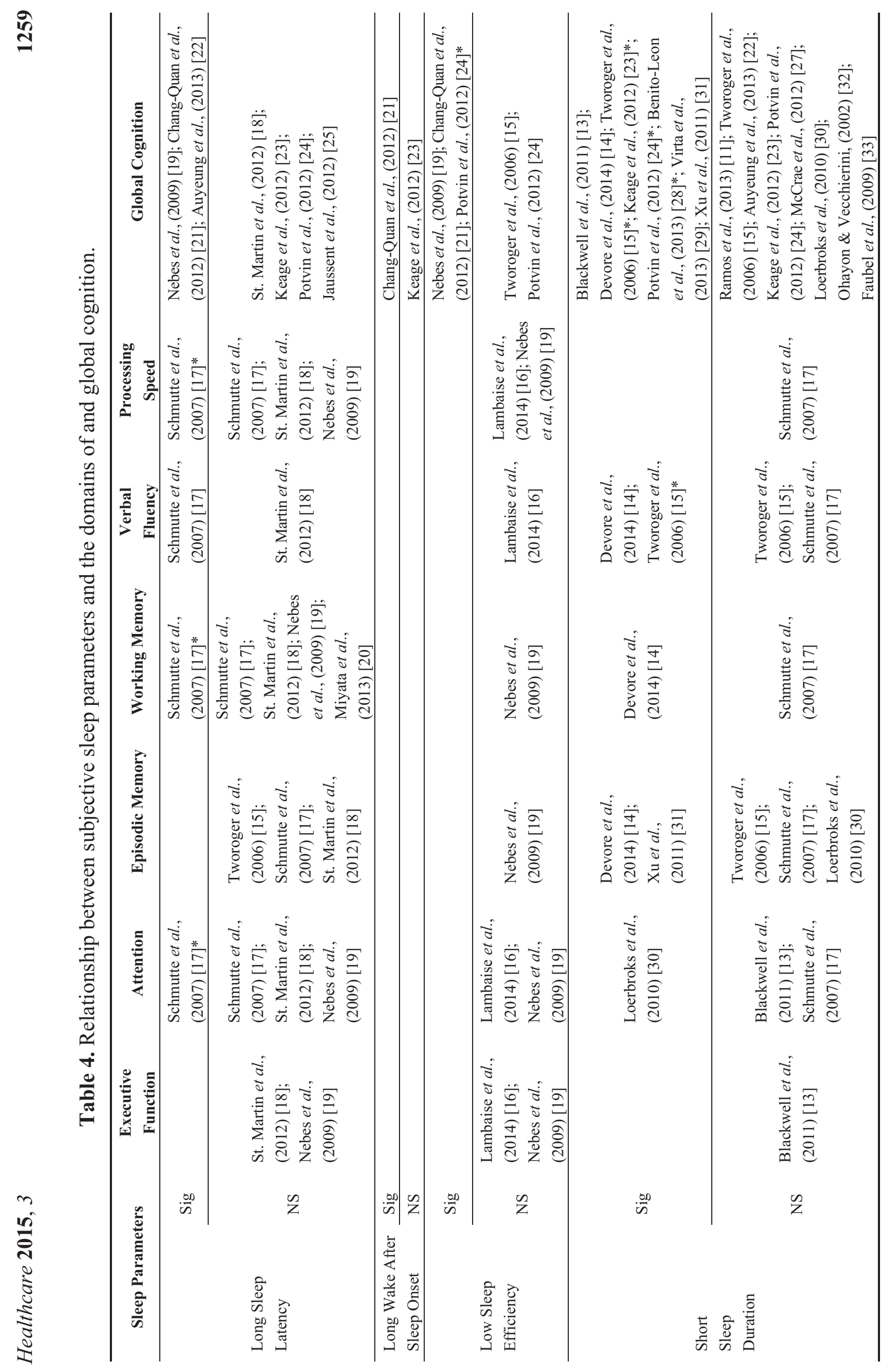




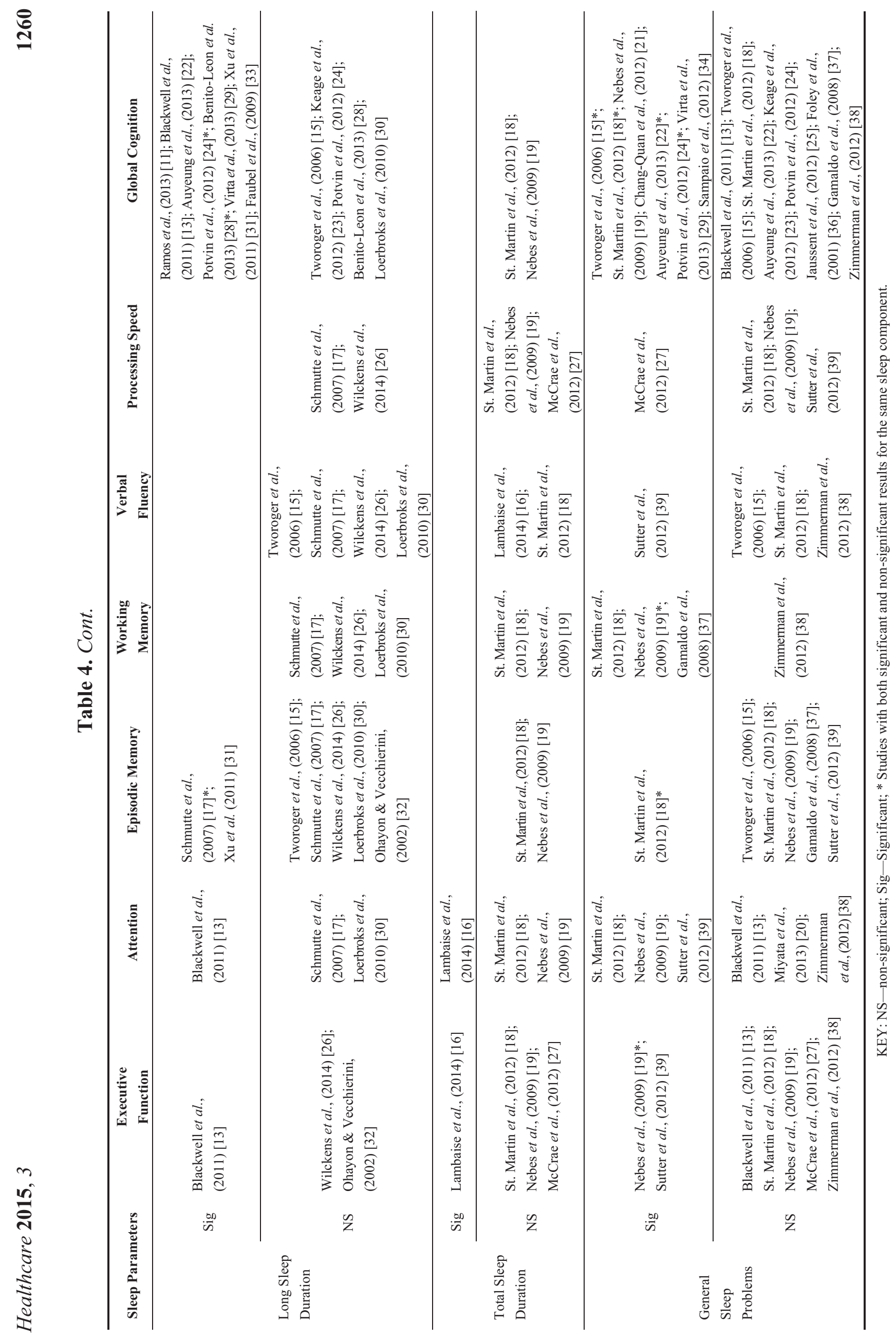




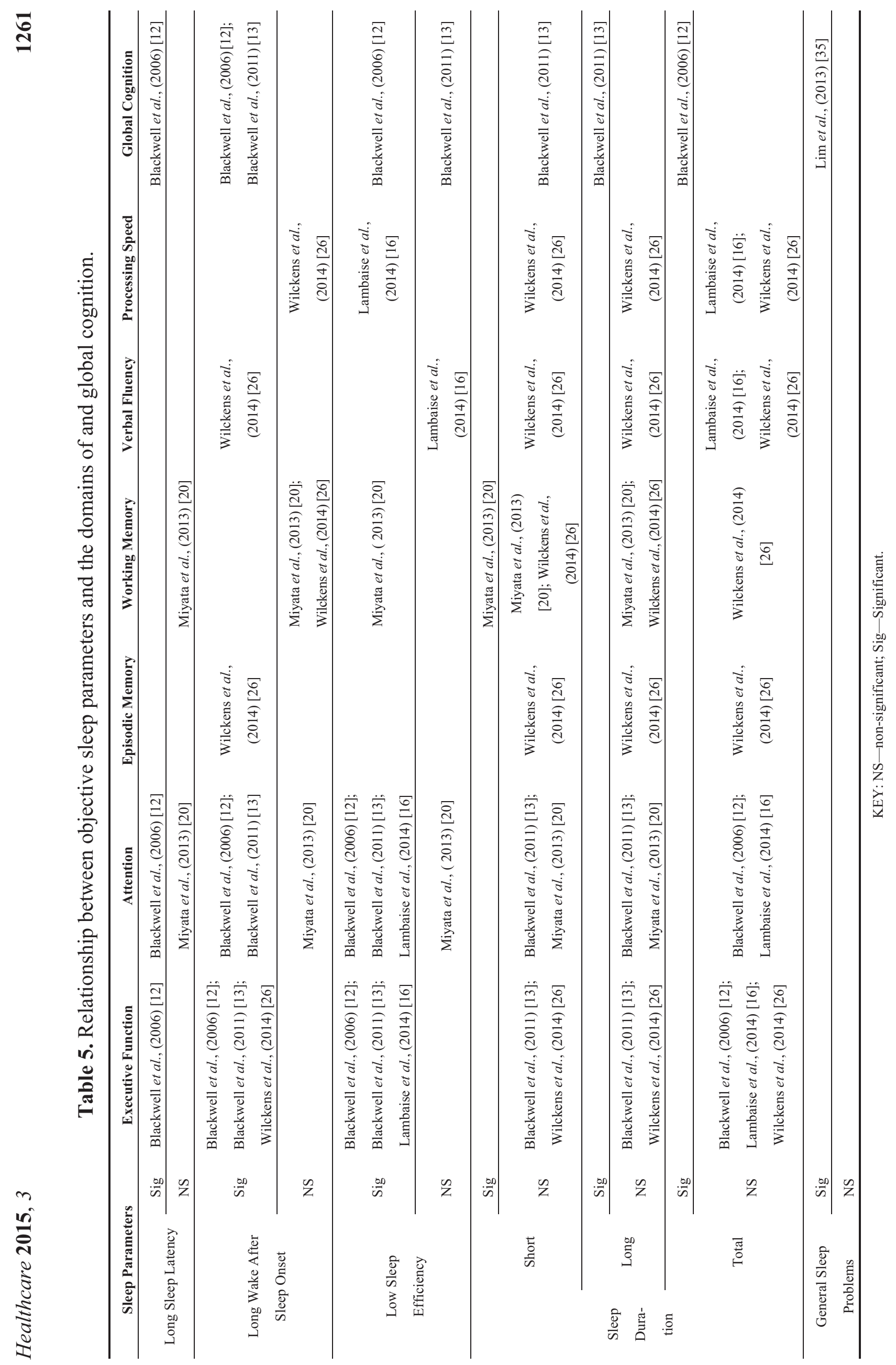




\subsection{Sleep Latency}

Sleep latency is the amount of time (usually in minutes) it takes a person to fall asleep, starting from the first intention to fall asleep. The studies with sleep latency and cognition in older adults have reported mixed results. The results suggest a greater link between sleep latency and global cognition than sleep latency and the particular domains of cognition. Schmutte, et al. [17] reported that in a cross-sectional study, while longer sleep latency was associated with worse performance on measures of attention, working memory, verbal fluency and processing speed, after multivariate adjustment, longer sleep latency was associated with verbal fluency only. Findings from three other studies did not indicate a relationship between sleep latency and executive function [18,19], attention [18,19], episodic memory $[15,17,18]$, working memory [18-20], verbal fluency [18] and processing speed [18,19]. Three cross sectional studies reported that longer sleep latency was associated with worse performance on global cognition measures [19,21,22], while four other studies [18,23-25] reported no relationship between the two variables. When examining objective reports, Blackwell, et al. [12] reported that longer sleep latency was associated with worse executive function, attention and global cognition while Miyata, et al. [20] did not find any association between sleep latency and attention or working memory.

\subsection{Wake after Sleep Onset}

Wake after sleep onset is total amount of time awake during the night, from the time the person falls asleep until final awakening. There is potential evidence to support the relationship between longer wake after sleep onset and worse domain-specific and global cognition. In two gender-specific studies using actigraphy, wake after sleep onset was associated with worse global cognitive function in both men and women after adjustment for depression and multiple demographic, physical, and health factors $[12,13]$. Longer wake after sleep onset, derived from the PSQI, was also associated with worse global cognition [21]. However, when using an investigator-developed questionnaire to assess sleep, Keage, et al. [23] reported that longer wake after sleep onset was not associated cross-sectionally or longitudinally with global cognitive function. No study examined the association between subjective wake after sleep onset and the domains of cognition; however, longer wake after sleep onset, examined objectively, was associated with worse performance in tests of executive function [12,13,26], attention [12,13], episodic memory [26], and verbal fluency [26] and global cognition [12,13]. In other studies, wake after sleep onset was not associated with attention [20], working memory [20,26] and processing speed [26]. Discrepant finding could be due to using different measures to assess the wake after sleep onset or the cognitive domains.

\subsection{Sleep Efficiency}

Sleep efficiency is the ratio of the time a person is sleeping to the time that is actually spent in bed trying to sleep. The studies with sleep efficiency and cognition suggest that there is a relationship between subjective and objective measured sleep efficiency and global cognition. When looking at the domains of cognition, there appears to be a relationship between the domains and objectively assessed sleep but not subjectively assessed sleep. Using the PSQI, Chang-Quan, et al. [21] and Nebes, et al. [19] reported that, based on cross-sectional analyses, as sleep efficiency decreased, global cognitive function worsened. Similarly, Potvin, et al. [24] reported that longitudinally as sleep efficiency decreased, measured with the 
PSQI, global cognitive function worsened; however, the association was significant for male but not female participants. Using an investigator-developed questionnaire, Tworoger, et al. [15] reported no longitudinal relationship between sleep efficiency and global cognitive function. In objective assessments, there were contrasting results reported by the two Blackwell and colleagues' studies: in the study with only female participants [12] they found that a relationship was present between the two variables, while in the study with only male participants [13] there was no association between the variables.

As objective sleep efficiency decreased, executive function $[12,13,16]$, attention $[12,13,16]$, working memory [20] and processing speed [16] worsened. There was no relationship between sleep efficiency and attention [20] and verbal fluency [16]. Subjectively measured sleep efficiency was not associated with executive function [16,19], attention [16,19], episodic memory [19], working memory [19], verbal fluency [16] and processing speed [16,19]. Since all the studies were cross-sectional, the difference in the results could be due to different studies using only one measure or multiple measures for the same domain. For example, Nebes, et al. [19] used multiple measures to evaluate executive function while the two studies by Blackwell, et al. $[12,13]$ each only used one measure.

\subsection{Sleep Duration}

In some of the studies, sleep duration was examined as a continuous variable while in other studies sleep duration was dichotomized into short and long sleep duration. When sleep was examined as a continuous variable, there was no relationship between sleep duration and the domains of and global cognition. However, a U-shaped relationship appeared to emerge when sleep duration was dichotomized and results suggest a relationship between short and long sleep and domains of cognition and global cognition. In a study with older women, Lambiase, et al. [16] reported that subjectively measured total sleep duration was associated with executive function and attention but not processing speed; while, objectively measured sleep duration was not associated with any of the cognitive domains. Wilckens, et al. [26] had similar results with no association between objectively measured total sleep duration and executive function, episodic memory, working memory and processing speed in a cross-sectional assessment of older adults. Blackwell, et al. [13] also found no association between objectively measured total sleep duration and executive function and attention. In subjective assessment, total sleep duration was not associated with executive function [18,19,27], attention [18,19], episodic memory [18,19], working memory [18,19], processing speed [18,19,27] and global cognition [18,19].

In terms of subjective short sleep duration and global cognition, Potvin, et al. [24] had mixed results based on gender. Men with short sleep duration had worse global cognition after one year while there was no longitudinal relationship between short sleep duration and global cognition in women. Benito-León, et al. [28] reported that there was a cross-sectional association between short sleep and global cognitive function; however, this association was no longer present at the 3-year follow-up. Tworoger, et al. [15] had similar results in their cross-sectional and longitudinal (2 years) analyses. In longitudinal analyses, after 22.5 years, Virta, et al. [29] found that short sleep duration was associated with poorer cognition. Keage, et al. [23] had contrasting results with no association between short sleep and global cognitive function at baseline but an association between short sleep and global cognitive impairment at two and 10 years. Loerbroks, et al. [30] found no cross-sectional nor longitudinal association between short sleep duration and global cognitive function. While Blackwell, et al. [13], 
Devore, et al. [14], and $\mathrm{Xu}$, et al. [31] reported cross-sectional association between subjective short sleep and global cognition, other researchers, Auyeung, et al. [22], Ohayon and Vecchierini [32], Ramos, et al. [11], Faubel, et al. [33] and McCrae, et al. [27] had contrasting results.

When looking at the domains of cognition, subjective short sleep duration was associated with attention [30], episodic memory [14,31], working memory [14] and verbal fluency [14]. In contrast, short sleep duration was not related to executive function [13], attention [13,17], episodic memory [15,17,30], working memory [17], verbal fluency [17], and processing speed [17]. Tworoger, et al. [15] reported an association between short sleep duration and verbal fluency at baseline, which was no longer significant at follow-up. In objective findings, Miyata, et al. [20] reported a relationship between short sleep duration and working memory using the 0-back test. However, using the 1-back test, there was no relationship between the two vaiables. None of the other studies that looked short sleep duration and domains of cogniton found an association $[13,20,26]$. These studies also did not find associations with objective long sleep duration and the domains of cogniton.

Potvin, et al. [24] found that in women but not men, long sleep duration was associated with incident cognitive impairment over one year. Virta, et al. [29] found that long sleep was associated with poorer cognition in a 22.5 year follow up of older adults. Benito-León, et al. [28] reported that while there was no cross-sectional relationship between long sleep duration and global cognitive function, a relationship emerged between the two variables at the three year follow-up. Ramos, et al. [11], Blackwell, et al. [13], Auyeung, et al. [22], Faubel, et al. [33], and Xu, et al. [31] reported relationships between long sleep duration and worse global cognitive function; while, Tworoger, et al. [15], Keage, et al. [23], Ohayon and Vecchierini [32] and Loerbroks, et al. [30] reported that long sleep duration was not related to global cognitive function.

\subsection{General Sleep Problems}

There are mixed findings in the relationship between general sleep problems and domains of cognition and global cognition but imply a possible link between increased sleep problems and reduced cognition. In the study by Potvin, et al. [24], the sleep quality score in men and the sleep disturbance score in women were associated with global cognition while there was no association between the sleep quality score in women and the sleep disturbance score in men with global cognition. Tworoger, et al. [15] reported that there was a cross-sectional but not longitudinal relationship between general sleep problems and global cognition. Saint Martin, et al. [18] reported that the global PSQI score was associated with worse global cognition; while, the PSQI sleep quality score was not associated with global cognition. Auyeung, et al. [22] revealed that in univariate analyses sleep problems were associated with global cognition but were no longer associated after multivariate analyses. Nebes, et al. [19], Sampaio, et al. [34], Virta, et al. [29] and Chang-Quan, et al. [21] reported that there was a relationship between subjective general sleep problems and global cognition and Lim, et al. [35] reported that there was a relationship between objective general sleep problems and global cognition. In contrast, Blackwell, et al. [13], Keage, et al. [23], Jaussent, et al. [25], Foley, et al. [36], Gamaldo, et al. [37] and Zimmerman, et al. [38] reported no associations between subjectively measured general sleep problems and global cognition.

There are conflucting results for general sleep problems and each of domains of cognition. Saint Martin, et al. [18], Nebes, et al. [19], Gamaldo, et al. [37], Sutter, et al. [39] and McCrae, et al. [27] 
all reported an association with general sleep complaints and at least one of the domain of cognition while Saint Martin, et al. [18], Nebes, et al. [19], Sutter, et al. [39] and McCrae, et al. [27] in addition to Zimmerman, et al. [38], Blackwell, et al. [13], Miyata, et al. [20] and Tworoger, et al. [15] reported that there was no relationship between the variables.

\section{Discussion}

The aim of the review was to understand the relationship between sleep parameters and the domains of cognition and global cognition in adults 60 years and older. In this population, the research on the association of subjective sleep parameters and cognition is mixed; as a result, more studies, particularly longitudinal studies, are needed that further explores the relationship among these variables. Interestingly, sleep duration, a sleep variable most consistently related to disease states such as cardiovascular disease [44,45], was not consistently associated with changes in cognitive function. A recent review suggests that older adults may actually be more resistant to the cognitive effects of sleep problems, such as deprivation and restriction [46] possibly due to physiologic adaptation throughout the aging process.

A majority of the studies used available data as partial measures of sleep, as many of these studies were secondary analyses. These measures often were not validated or demonstrated to be reliable and thus cannot be readily compared against other valid and reliable measures of sleep. Even in studies with good measures of sleep, the measure primarily reflected an overarching score of sleep. For instance, the PSQI assesses sleep with a single score reflecting overall sleep in the last month. In addition, sleep parameters were assessed differently by different questionnaires. For example, sleep latency was assessed by asking the participants to indicate the number of minutes taken to fall asleep or by asking if they usually took long to fall asleep. There was also a lack of standardization of the cut-off times for some of the sleep variables such as sleep latency and sleep duration. For example, Ohayon and Vecchierini [32] used short sleep duration as $<7 \mathrm{~h}$ and long sleep duration as $>8.5 \mathrm{~h}$ while Loerbroks, et al. [30] defined short sleep duration as $<6 \mathrm{~h}$ and long sleep duration as $>9 \mathrm{~h}$. Future studies should attempt to standardize the cut-points used for long and short sleep duration. Another limitation is the use of subjective sleep measures in many studies of cognitive function. Subjective measures can possibly lead to differential misclassification and selective drop-out, because persons with poor cognitive function are likely to have more difficulty to accurately complete sleep questionnaires and sleep diaries.

Objective sleep measures are necessary, but have their own strengths and weakness. For example, actigraphy provides a plethora of activity data over longer periods of time but is often not sensitive to time spent awake lying still and does not measure sleep stage [47]; whereas polysomnography (PSG) uses many physiologic measures to capture sleep and sleep parameters but is often only completed on one or two nights [48]. Sleep in older adults is quite variable and the influence of that factor was generally not accounted for in the reviewed studies. Examining the relationship between night to night sleep variability using multi-night objective measures of sleep is necessary to further assess the relationship between objective sleep and cognition.

Sleep architecture parameters specific to rapid eye movement (REM) and non-rapid eye movement (nREM) sleep were not examined in this review. Since older adults report increase in sleep fragmentation and more time in lighter sleep stages [49], it is possible that these parameters are the ones that are more associated with changes in cognitive function. In order to determine if there is an association, PSG needs 
to be used on a more consistent basis. Home polysomnography is now an option and may be better and more convenient for the participants.

The inconsistency of measurement of cognition and sleep also limits the ability to identify relationships across the reviewed studies. First, there was variation across the studies in the assessment measures for sleep and cognitive function. Although the measures used for cognitive function in the majority of studies were valid and reliable, the same measure was not consistently used by the researchers to examine global or domains of cognition. For example, Trail Making B, Stroop Color and Word test, Oral Word Fluency test, Porteus Maze, and Optimal Telegram were all used to assess executive function. As pointed out by Snowden, et al. [50], it would be beneficial if there was a consensus of measures, such as the National Institutes of Health Toolbox or the Uniform Data Set of the Alzheimer's Disease Center, to allow for better comparison across studies. Another limitation within the cognitive domain involves the measures used to assess global cognitive functioning. Many of the measures, like the MMSE, may not be sensitive enough to identify small but significant changes in cognition.

Additionally, there are important covariates that must be accounted for in studying the relationship between sleep parameters and cognition. Depression is a common cause of sleep problems in older adults and associated with neurocognitive impairments such as slower processing speed and executive dysfunction [51]. Aloia, et al. [52], Steffens, et al. [53] and Zimmerman, et al. [38] have also posited that depression and depressive symptoms are associated with a decline in cognitive function. In their review, Foley, et al. [36] reported that sleep problems did not predict cognitive decline after controlling for depression; however, depression at baseline significantly increased the likelihood of a decline in cognitive function at follow-up. Schmutte, et al. [17] reported that sleep latency and total sleep time were moderately related to depression and Saint Martin, et al. [18] reported that subjective evaluation of cognitive function was related to the depression score. Nebes, et al. [19] pointed out that the participants who reported poor sleep had more depressive symptomatology than those reporting good sleep; therefore, it is possible that poorer sleep was related to depression which then contributed to poorer cognitive functioning for that specific group of older adults.

Another alternative explanation is that study participants with undiagnosed sleep apnea may have contributed to the inconsistency in the association between sleep parameters and cognitive function. Most studies in the review did not screen for or ask about a sleep apnea diagnosis or had sleep apnea as a confounder, so did not account for the possible confounding effect of the presence of sleep apnea. Sleep apnea is associated with worse verbal fluency and constructional tasks [52] and without a screen or diagnosis, it is challenging to adjust for the presence of the disorder or symptoms.

Both age and poorer health appear to play a role in the relationship between sleep and cognition. Blackwell, et al. [12], Chang-Quan, et al. [21] and Lim, et al. [35] all reported that participants with a mean age over 80 years old reported that the worse the sleep parameters, the worse their cognitive function measures. Denton and Spencer [54] reported that in the oldest old population, the prevalence rate and the relative prevalence of chronic conditions such as dementia, stroke, and heart disease were much higher for persons over 80 years than for persons under age 80. Wolff, et al. [55] also reported than adults over 80 years were more likely to have more than four chronic illnesses compared to their younger counterparts. Kronholm, et al. [56] reported that the relationship between sleep and cognitive function disappeared when they accounted for the participants' health status. 


\section{Conclusions}

The current research on the association of subjective sleep parameters and cognition is inconclusive and there is insufficient evidence to confirm or deny the existence of a relationship between objective sleep parameters and cognition. Primary studies using valid and reliable measures for all sleep and cognitive variables are clearly needed; it would be very useful if similar measures were used across studies. Future research should also account for important covariates such as depression, obstructive sleep apnea, age and chronic medical illness. Healthcare providers should be aware that sleep disturbances can be associated with cognition in older adults and that medical and psychiatric conditions can influence the association. With this knowledge, providers should perform baseline and periodic ongoing assessments to identify changes in sleep patterns, cognition, and the risk factors that can influence the association between sleep and cognition.

\section{Acknowledgments}

Funding for Glenna Brewster came from the National Hartford Center for Gerontological Nursing Excellence and she is currently sponsored by the National Institutes of Health, National Research Service Award (T32HL07713). Predoctoral fellowship support for Miranda Varrasse is sponsored by the National Institutes of Health, Ruth L. Kirschstein National Research Service Award (T32NR009356).

\section{Author Contributions}

Glenna S. Brewster worked on all aspects of the review; Miranda Varrasse worked on the methods section, reviewed all references for inclusion/exclusion and edited all sections of the review; and Meredeth Rowe edited the document and worked on the results and conclusion of the review.

\section{Conflicts of Interest}

The authors declare no conflict of interest.

\section{References}

1. Salthouse, T. Consequences of age-related cognitive declines. Annu. Rev. Psychol. 2012, 63, 201-226.

2. Ohayon, M.M.; Carskadon, M.A.; Guilleminault, C.; Vitiello, M.V. Meta-analysis of quantitative sleep parameters from childhood to old age in healthy individuals: Developing normative sleep values across the human lifespan. Sleep 2004, 27, 1255-1273.

3. Glisky, E.L. Changes in cognitive function in human aging. In Brain Aging: Models, Methods, and Mechanisms; Riddle, D.R., Ed.; CRC Press: Boca Raton, FL, USA, 2007.

4. Vitiello, M.V. Sleep in normal aging. Sleep Med. Clin. 2006, 1, 171-176.

5. Shapiro, C.M.; Flanigan, M.J. ABC of sleep disorders. Function of sleep. BMJ 1993, 306, 383-385.

6. National Heart, Lung, and Blood Institute. Why is sleep important? Available online: http://www.nhlbi.nih.gov/health/health-topics/topics/sdd/why.html (accessed on 1 March 2015). 
7. Cricco, M.; Simonsick, E.M.; Foley, D.J. The impact of insomnia on cognitive functioning in older adults. J. Am. Geriatr. Soc. 2001, 49, 1185-1189.

8. Stickgold, R. Sleep-dependent memory consolidation. Nature 2005, 437, 1272-1278.

9. Scullin, M.K.; Bliwise, D.L. Sleep, cognition, and normal aging: Integrating a half century of multidisciplinary research. Perspect. Psychol. Sci. 2015, 10, 97-137.

10. Yaffe, K.; Falvey, C.M.; Hoang, T. Connections between sleep and cognition in older adults. Lancet Neurol. 2014, 13, 1017-1028.

11. Ramos, A.R.; Dong, C.; Elkind, M.S.; Boden-Albala, B.; Sacco, R.L.; Rundek, T.; Wright, C.B. Association between sleep duration and the mini-mental score: The northern manhattan study. J. Clin. Sleep Med. 2013, 9, 669-673.

12. Blackwell, T.; Yaffe, K.; Ancoli-Israel, S.; Scheider, J.L.; Cauley, J.A.; Hillier, T.A.; Fink, H.A.; Stone, K.L.; Grp, S.O.F. Poor sleep is associated with impaired cognitive function in older women: The study of osteoporotic fractures. J. Gerontol. Ser. A 2006, 61, 405-410.

13. Blackwell, T.; Yaffe, K.; Ancoli-Israel, S.; Redline, S.; Ensrud, K.E.; Stefanick, M.L.; Laffan, A.; Stone, K.L.; Osteoporotic Fractures in Men Study Group. Associations between sleep architecture and sleep-disordered breathing and cognition in older community-dwelling men: The osteoporotic fractures in men sleep study. J. Am. Geriatr. Soc. 2011, 59, 2217-2225.

14. Devore, E.E.; Grodstein, F.; Duffy, J.F.; Stampfer, M.J.; Czeisler, C.A.; Schernhammer, E.S. Sleep duration in midlife and later life in relation to cognition. J. Am. Geriatr. Soc. 2014, 62, 1073-1081.

15. Tworoger, S.S.; Lee, S.; Schernhammer, E.S.; Grodstein, F. The association of self-reported sleep duration, difficulty sleeping, and snoring with cognitive function in older women. Alzheimer Dis. Assoc. Disord. 2006, 20, 41-48.

16. Lambiase, M.J.; Gabriel, K.P.; Kuller, L.H.; Matthews, K.A. Sleep and executive function in older women: The moderating effect of physical activity. J. Gerontol. A 2014, 69, 1170-1176.

17. Schmutte, T.; Harris, S.; Levin, R.; Zweig, R.; Katz, M.; Lipton, R. The relation between cognitive functioning and self-reported sleep complaints in nondemented older adults: Results from the bronx aging study. Behav. Sleep Med. 2007, 5, 39-56.

18. Saint Martin, M.; Sforza, E.; Barthelemy, J.C.; Thomas-Anterion, C.; Roche, F. Does subjective sleep affect cognitive function in healthy elderly subjects? The proof cohort. Sleep Med. 2012, 13, $1146-1152$.

19. Nebes, R.D.; Buysse, D.J.; Halligan, E.M.; Houck, P.R.; Monk, T.H. Self-reported sleep quality predicts poor cognitive performance in healthy older adults. J. Gerontol. B 2009, 64, 180-187.

20. Miyata, S.; Noda, A.; Iwamoto, K.; Kawano, N.; Okuda, M.; Ozaki, N. Poor sleep quality impairs cognitive performance in older adults. J. Sleep Res. 2013, 22, 535-541.

21. Chang-Quan, H.; Bi-Rong, D.; Yan, Z. Association between sleep quality and cognitive impairment among chinese nonagenarians/centenarians. J. Clin. Neurophysiol. 2012, 29, 250-255.

22. Auyeung, T.W.; Lee, J.S.W.; Leung, J.; Kwok, T.; Leung, P.C.; Woo, J.; Wing, Y.K. Cognitive deficit is associated with phase advance of sleep-wake rhythm, daily napping, and prolonged sleep duration-A cross-sectional study in 2947 community-dwelling older adults. Age 2013, 35, 479-486.

23. Keage, H.A.; Banks, S.; Yang, K.L.; Morgan, K.; Brayne, C.; Matthews, F.E. What sleep characteristics predict cognitive decline in the elderly? Sleep Med. 2012, 13, 886-892. 
24. Potvin, O.; Lorrain, D.; Forget, H.; Dubé, M.; Grenier, S.; Préville, M.; Hudon, C. Sleep quality and 1-year incident cognitive impairment in community-dwelling older adults. Sleep 2012, 35, 491-499.

25. Jaussent, I.; Bouyer, J.; Ancelin, M.-L.; Berr, C.; Foubert-Samier, A.; Ritchie, K.; Ohayon, M.M.; Besset, A.; Dauvilliers, Y. Excessive sleepiness is predictive of cognitive decline in the elderly. Sleep 2012, 35, 1201-1207.

26. Wilckens, K.A.; Woo, S.G.; Kirk, A.R.; Erickson, K.I.; Wheeler, M.E. Role of sleep continuity and total sleep time in executive function across the adult lifespan. Psychol. Aging 2014, 29, 658-665.

27. McCrae, C.S.; Vatthauer, K.E.; Dzierzewski, J.M.; Marsiske, M. Habitual sleep, reasoning, and processing speed in older adults with sleep complaints. Cogn. Ther. Res. 2012, 36, 156-164.

28. Benito-León, J.; Louis, E.D.; Bermejo-Pareja, F. Cognitive decline in short and long sleepers: A prospective population-based study (NEDICES). J. Psychiatr. Res. 2013, doi:10.1016/j.jpsychires. 2013.1009.1007.

29. Virta, J.J.; Heikkila, K.; Perola, M.; Koskenvuo, M.; Raiha, I.; Rinne, J.O.; Kaprio, J. Midlife sleep characteristics associated with late life cognitive function. Sleep 2013, 36, 1533-1541.

30. Loerbroks, A.; Debling, D.; Amelang, M.; Sturmer, T. Nocturnal sleep duration and cognitive impairment in a population-based study of older adults. Int. J. Geriatr. Psychiatry 2010, 25, 100-109.

31. Xu, L.; Jiang, C.Q.; Lam, T.H.; Zhang, W.S.; Cherny, S.S.; Thomas, G.N.; Cheng, K.K. Sleep duration and memory in the elderly chinese: Longitudinal analysis of the guangzhou biobank cohort study. Sleep 2014, 37, 1737-1744.

32. Ohayon, M.M.; Vecchierini, M.F. Daytime sleepiness and cognitive impairment in the elderly population. Arch. Intern. Med. 2002, 162, 201-208.

33. Faubel, R.; López-García, E.; Guallar-Castillón, P.; Graciani, A.; Banegas, J.R.; Rodríguez-Artalejo, F. Usual sleep duration and cognitive function in older adults in spain. J. Sleep Res. 2009, 18, 427-435.

34. Sampaio, R.A.C.; Sewo Sampaio, P.Y.; Yamada, M.; Tsuboyama, T.; Arai, H. Self-reported quality of sleep is associated with bodily pain, vitality and cognitive impairment in japanese older adults. Geriatr. Gerontol. Int. 2014, 14, 628-635.

35. Lim, A.S.; Kowgier, M.; Yu, L.; Buchman, A.S.; Bennett, D.A. Sleep fragmentation and the risk of incident alzheimer's disease and cognitive decline in older persons. Sleep 2013, 36, 1027-1032.

36. Foley, D.; Monjan, A.; Masaki, K.; Ross, W.; Havlik, R.; White, L.; Launer, L. Daytime sleepiness is associated with 3-year incident dementia and cognitive decline in older japanese-american men. J. Am. Geriatr. Soc. 2001, 49, 1628-1632.

37. Gamaldo, A.A.; Allaire, J.C.; Whitfield, K.E. Exploring the within-person coupling of sleep and cognition in older african americans. Psychol. Aging 2010, 25, 851-857.

38. Zimmerman, M.E.; Bigal, M.E.; Katz, M.J.; Brickman, A.M.; Lipton, R.B. Sleep onset/maintenance difficulties and cognitive function in nondemented older adults: The role of cognitive reserve. J. Int. Neuropsychol. Soc. 2012, 18, 461-470.

39. Sutter, C.; Zollig, J.; Allemand, M.; Martin, M. Sleep quality and cognitive function in healthy old age: The moderating role of subclinical depression. Neuropsychology 2012, 26, 768-775.

40. Buysse, D.J.; Reynolds, C.F., 3rd; Monk, T.H.; Berman, S.R.; Kupfer, D.J. The pittsburgh sleep quality index: A new instrument for psychiatric practice and research. Psychiatry Res. 1989, 28, 193-213.

41. Folstein, M.F.; Folstein, S.E.; McHugh, P.R. "Mini-mental state". A practical method for grading the cognitive state of patients for the clinician. J. Psychiatr. Res. 1975, 12, 189-198. 
42. Clark, C.A.; Nelson, J.M.; Garza, J.; Sheffield, T.D.; Wiebe, S.A.; Espy, K.A. Gaining control: Changing relations between executive control and processing speed and their relevance for mathematics achievement over course of the preschool period. Front. Psychol. 2014, doi:10.3389/fpsyg.2014.00107.

43. Dickinson, D.; Coursey, R.D. Independence and overlap among neurocognitive correlates of community functioning in schizophrenia. Schizophr. Res. 2002, 56, 161-170.

44. Ayas, N.T.; White, D.P.; Manson, J.E.; Stampfer, M.J.; Speizer, F.E.; Malhotra, A.; Hu, F.B. A prospective study of sleep duration and coronary heart disease in women. Arch. Intern. Med. 2003, 163, 205-209.

45. Sabanayagam, C.; Shankar, A. Sleep duration and cardiovascular disease: Results from the national health interview survey. Sleep 2010, 33, 1037-1042.

46. Pace-Schott, E.F.; Spencer, R.M. Age-related changes in the cognitive function of sleep. Prog. Brain Res. 2011, 191, 75-89.

47. Morgenthaler, T.; Alessi, C.; Friedman, L.; Owens, J.; Kapur, V.; Boehlecke, B.; Brown, T.; Chesson, A., Jr.; Coleman, J.; Lee-Chiong, T.; et al. Practice parameters for the use of actigraphy in the assessment of sleep and sleep disorders: An update for 2007. Sleep 2007, 30, 519-529.

48. Kushida, C.A.; Littner, M.R.; Morgenthaler, T.; Alessi, C.A.; Bailey, D.; Coleman, J., Jr.; Friedman, L.; Hirshkowitz, M.; Kapen, S.; Kramer, M.; et al. Practice parameters for the indications for polysomnography and related procedures: An update for 2005. Sleep 2005, 28, 499-521.

49. National Sleep Foundation (NSF). 2003 Sleep in America Poll; NSF: Arlington, VA, 2003.

50. Snowden, M.; Steinman, L.; Mochan, K.; Grodstein, F.; Prohaska, T.R.; Thurman, D.J.; Brown, D.R.; Laditka, J.N.; Soares, J.; Zweiback, D.J.; et al. Effect of exercise on cognitive performance in community-dwelling older adults: Review of intervention trials and recommendations for public health practice and research. J. Am. Geriatr. Soc. 2011, 59, 704-716.

51. Thomas, A.J.; O’Brien, J.T. Depression and cognition in older adults. Curr. Opin. Psychiatry 2008, $21,8-13$.

52. Aloia, M.S.; Ilniczky, N.; di Dio, P.; Perlis, M.L.; Greenblatt, D.W.; Giles, D.E. Neuropsychological changes and treatment compliance in older adults with sleep apnea. J. Psychosom. Res. 2003, 54, 71-76.

53. Steffens, D.C.; Otey, E.; Alexopoulos, G.S.; Butters, M.A.; Cuthbert, B.; Ganguli, M.; Geda, Y.E.; Hendrie, H.C.; Krishnan, R.R.; Kumar, A.; et al. Perspectives on depression, mild cognitive impairment, and cognitive decline. Arch. Gen. Psychiatry 2006, 63, 130-138.

54. Denton, F.T.; Spencer, B.G. Chronic health conditions: Changing prevalence in an aging population and some implications for the delivery of health care services. Can. J. Aging 2010, 29, 11-21.

55. Wolff, J.L.; Starfield, B.; Anderson, G. Prevalence, expenditures, and complications of multiple chronic conditions in the elderly. Arch. Intern. Med. 2002, 162, 2269-2276.

56. Kronholm, E.; Sallinen, M.; Suutama, T.; Sulkava, R.; Era, P.; Partonen, T. Self-reported sleep duration and cognitive functioning in the general population. J. Sleep Res. 2009, 18, 436-446.

(C) 2015 by the authors; licensee MDPI, Basel, Switzerland. This article is an open access article distributed under the terms and conditions of the Creative Commons Attribution license (http://creativecommons.org/licenses/by/4.0/). 